\title{
Renovation of community cinemas as an opportunity
}

\begin{abstract}
:
The starting point of this essay is a multidisciplinary study conducted by the Department of Architecture and Urban Studies of the Politecnico di Milano regarding the opportunities for the revitalisation of the almost 800 Community Cinemas owned by the Italian Catholic Church. These cinemas represent the local communities and are an important part of the contemporary Italian urban environment. Research shows that cinemas are threatened by how people currently consume audio-visual content, that there is a need to rethink the projection theatres as social gathering spaces open to the twenty-first-century neighbourhood, thanks to some features innate in the Community Cinemas that can be enhanced. Four case studies have been identified that represent the most common (or widest variation of) size and general layout among the 800 existing situations. A general model has been developed through the radical re-shaping of the space in accordance with new urban and social functions and implementing new technologies. By designing these case-study project solutions, it was possible to define that a new model of multipurpose social centre merged with a more traditional projection room is not only possible, but thanks to state-of-the-art technologies could represent a perfect match and an opportunity to make significant changes throughout a community.
\end{abstract}

Keywords: Community Cinema, local communities, social space, multi-purpose space, cultural centre, adaptive building

\section{Introduction}

Over the past decade, we have witnessed a general transformation of how we normally consume audiovisual products such as movies, TV shows and other forms of multimedia content.

This massive change, from physical to digital distribution and spread of a multitude of media platforms, also has consequences in the way we have been used to imagine the space for the real-life gathering in order to share time together, for example watching a movie in a theatre. The great change came with the spread of digital platforms like Netflix or Amazon Prime Video, among the most widespread, and followed almost immediately the conclusion of another challenge for movie theatres, with the completion of the shift from analog to digital technology projections, almost completed in 2015 (Brunella, 2016, p.2). ${ }^{1}$ A great potential for innovation came together with the digital projector technology that allowed cinema managers to have a wide range of different content types to be presented to the audience. Considerations about this potential and the new challenge of web-based platforms led ACEC (Associazione Cattolica Esercenti Cinema, Catholic Association of Cinema Operators in English) to ask to the Department of Architecture and Urban Studies of the Politecnico di Milano to develop a research project about transformation and upgrade possibilities for the screening rooms that are part of ACEC association.

\section{Community Cinemas}

ACEC is the association that groups together cinemas owned in Italy by the Catholic Church. This typology of cinemas is called Sala della Comunità, which can be translated as Community Cinema. There are around 800 cinemas of this kind in Italy (Cipriani, Parrini, 2008). ${ }^{2}$ They started to appear in the 1920s, usually built close to a church, in the area of the oratory, due to the prompt understanding that the rising film projections could be an instrument of socialisation, evangelisation and fund raising for the charity activities of the parishes. Since then, they have survived many changes that endangered not only their role in society, but the very existence of the Community Cinemas: the spread of the television, the rise of the multiplex integrated to the shopping mall model imported from the United States, and the already mentioned shift to - digital projection, all extremely expensive for many small-business theatres.

The Community Cinemas established their presence in the urban fabric a long time ago, both from a physical (the presence of the cinema as a building) and a social point of view (the recognisability of the building as a gathering place). Their capacity to overcome hard times is based on their flexible and adaptive nature. In the first place, since the beginning, they have been hosting-mainly but not exclusively - movie projections; many of them also provide space for performances, live music and other performance arts; they host conference or various forms of meetings for the local community such as dancing, parties or school sessions. Moreover, even if they aim to have a self-sustainable annual budget, they are not merely a commercial business and volunteers from the parish members often manage them. It can be said that especially in the small centres and in the metropolitan suburbs, they provide the public function of the cul-

* Riccardo Maria Balzarotti, Fellow Researcher Architect, Politecnico di Milano, Department of Architecture and Urban Studies, ORCID: 0000-0001-5887-7612, e-mail: riccardomaria.balzarotti@polimi.it

** Luca Maria Francesco Fabris, Associate Professor, Politecnico di Milano, Department of Architecture and Urban Studies, ORCID: 0000-0001-5724-432X, e-mail: lucamariafrancesco.fabris@polimi.it| 
tural centre (Burlot, Fanchi, 2017). ${ }^{3}$ These realities are, in a dramatic vision, hidden jewels that are almost perfect already and that just need to shine again.

From an architectural point of view, it is not possible to isolate a specific typology of Community Cinema. Their size ranges from a small room inside an oratory with 40 seats to big theatres up to 600 seats; they can be located in some re-used space integrated in the general complex of the parish, or they can be separate and independent facilities purposely built as a cinema. It is also impossible to find a typical architectonic style or common features in the details and decorations, considering that they were built in different decades, different localities and according to the free will of the client (usually the parish priest) due to the absence of general rules or guidelines. The only common ground of the Community Cinemas lays in the sole idea of their function.

\section{Four case studies}

According to this variety of spaces and under the guidance of ACEC, four case studies were identified that could represent the size and the general layout with possibly the most common scenario among the 800 existing situations. The four different case-study projects analysed, correspond to four different urban environments - from a (post) rural village to a big city — are the following: the creation from scratch of a small cinema within an under-used space of the oratory in Guidizzolo (Mantua) (III. 1); the revitalisation of a medium size existing cine-theatre, abandoned for 20 years, in a separate and independent building in Mariano Comense (Como) (III. 2); the extension of a small currently operating cin- ema connecting an under-used and articulated succession of spaces to the main room in Sampierdarena (Genoa) (III. 3); the remodelling of a large and renowned cine-theatre into a multiplex in Bologna (III. 4).

After a first round of site surveys at the chosen locations and other Community Cinemas in the surrounding areas, it was possible to make a first observation. Even if, as we said, these places demonstrate a strong level of resilience thanks to their capacity to face the community requests from the point of view of the functional programme, they generally have a quite rigid structure in terms of space distribution. The schematic organisation is very simple and linear; in most cases, there is a single entrance, a foyer with a corner for the bar and just one projection room, often with too many seats for the current standards (Balzarotti, Fabris, 2018, pp. 22-29). ${ }^{4}$ A comparison with commercial cinemas in the same area showed that this schematic distribution is anachronistic for many reasons, mainly because the trend for commercial businesses is to have a main projection room that can be very large (up to 400 seats) and then as many small projection rooms as possible. This tendency is also confirmed by the comparison of the annual revenue between different activities: the higher is the number of the rooms in a single cinema, the higher are the earnings per room. ${ }^{5}$ One specific example of this new typology of recent multiplex is the 'Anteo Palazzo del Cinema' in Milan, opened in 2017 following a long and complex re-

III. 3. The urban fabric of Sampierdarena (Genoa)_-In the white circle is enlighten the Community Cinema building. Source. Prepared by R.M. Balzarotti, based on a 2020 Google Earth image

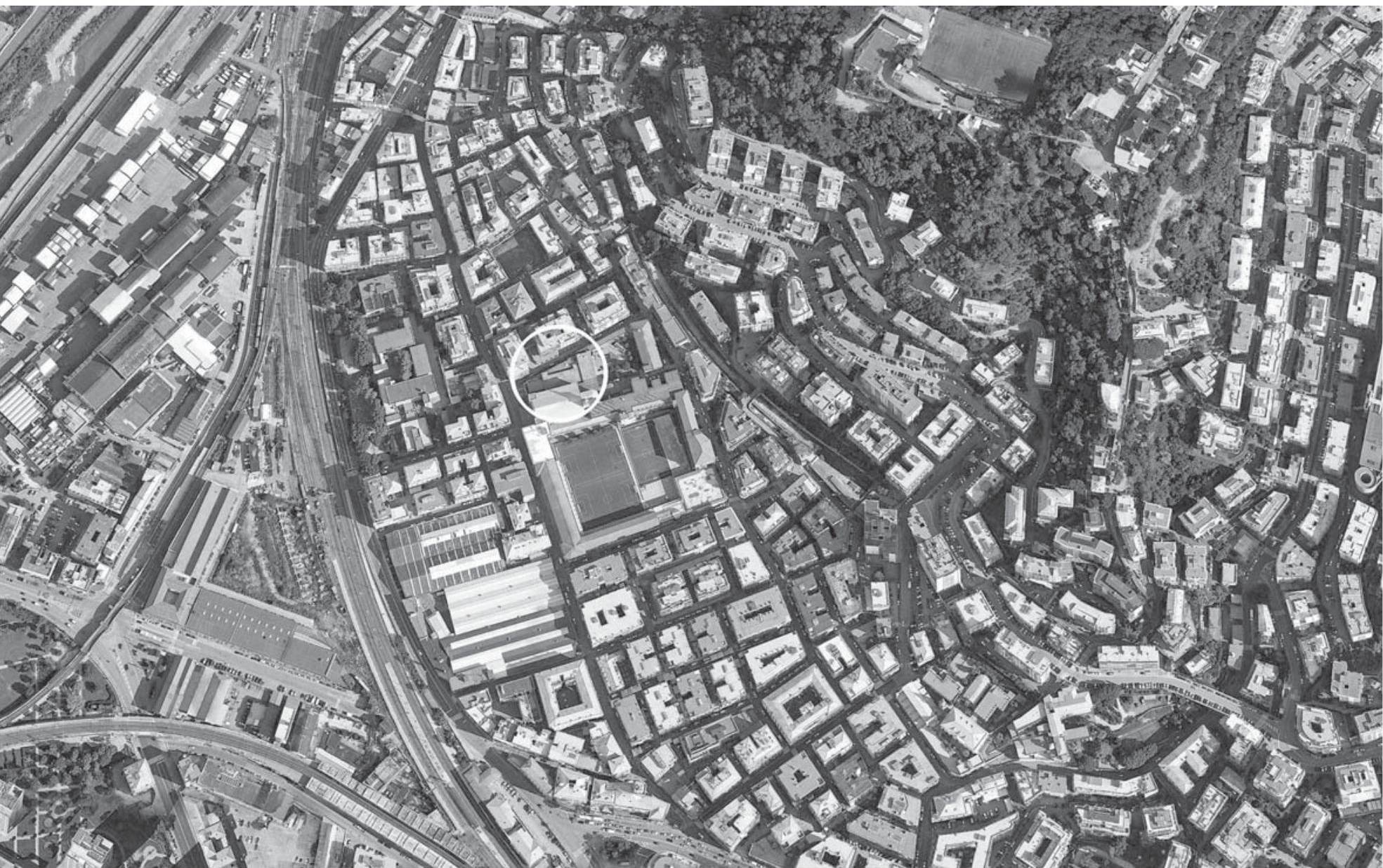




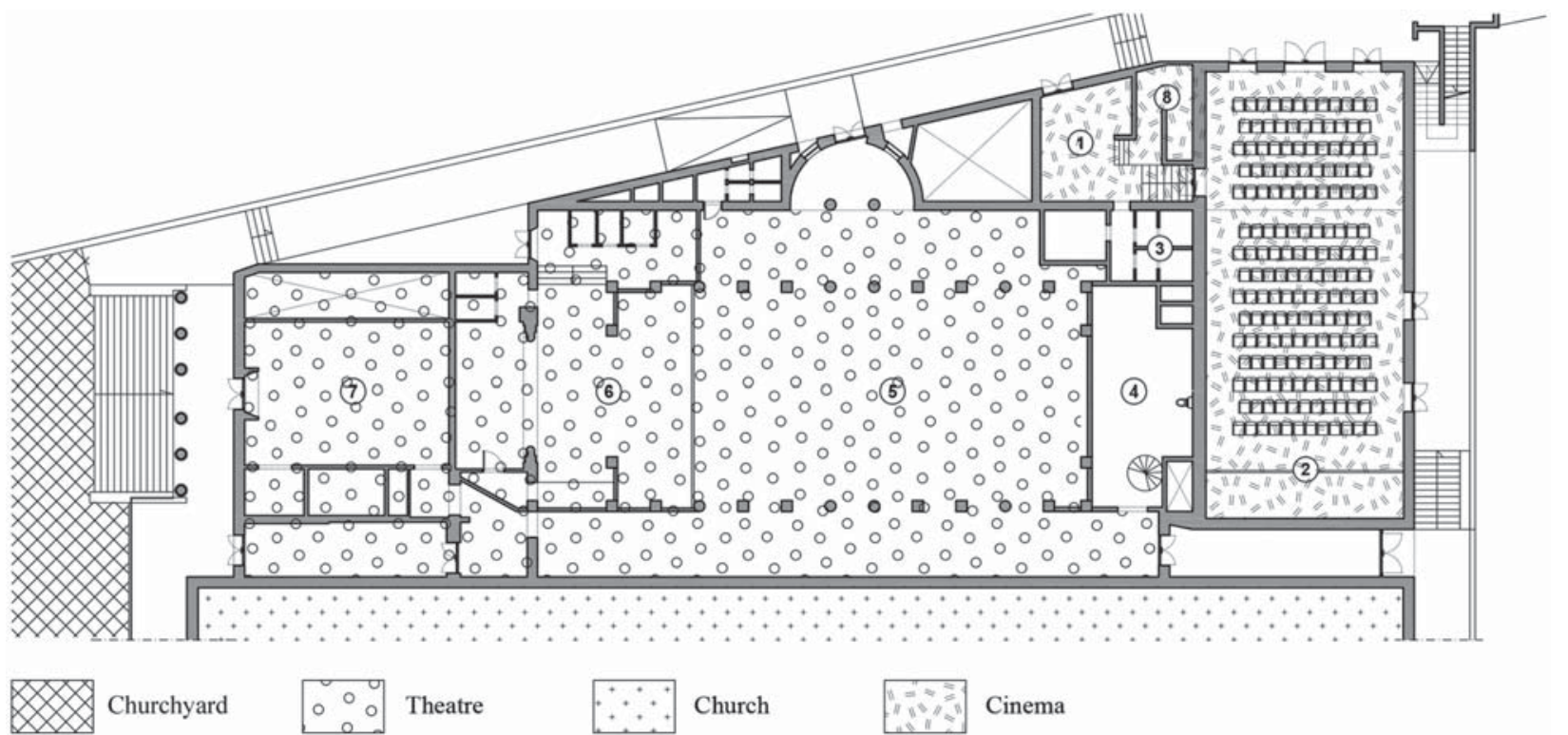

III. 8. Plan of the actual situation of the cinema complex in Sampierdarena. 1) Cinema entrance, 2) Projection room, 3) Toilets, 4) Storage, 5) Tempietto theatre, 6) Stage, 7) Lobby, 8) Access to the gallery. Prepared by R.M. Balzarotti, L.M.F. Fabris

projection room when the seats are completely open, while when the seats are retracted, it would become an empty space suitable for performing arts rehearsal, parties, exhibitions or other typologies of routines and didactic programmes. It is important to underline that the versatility of the space is directly linked with the life of the neighbourhood. The large space for rehearsal is a response to the needs of a specific space for dancing requested by the local Latin-American community. The possibility of hosting cinema classes would be useful to create synergies with the nearby schools. The meeting room would be an important service for the local associations that do not have a dedicated space at their disposal.
From the dense core of the multi-purpose a new corridor would lead to a stair used as a re-connection point with the existing cinema. The redesign would provide new technical spaces and a general renovation of the projection room with new materials, new lights and acoustic elements. It is also suggested to close the gallery, no longer accessible for safety reasons, and transform it in a modern and large projection booth, considering that the existing one is small, unsafe and hard to reach. The former foyer of the cinema, in the end, would become a new room designed to accommodate the office of the director, a function that could seem

III. 9. Plan of the renovation project. 1) Main entrance, 2) Ramp, 3) Foyer/Café, 4) Ticket office, 5) Meeting room, 6) Multi-purpose room, 7) Small lounge, 8) Direction office, 9) Staff, 10) Projection booth, 11) Toilets, 12) Cinema, 13) Access to the projection booth. Prepared by R.M. Balzarotti, L.M.F. Fabris

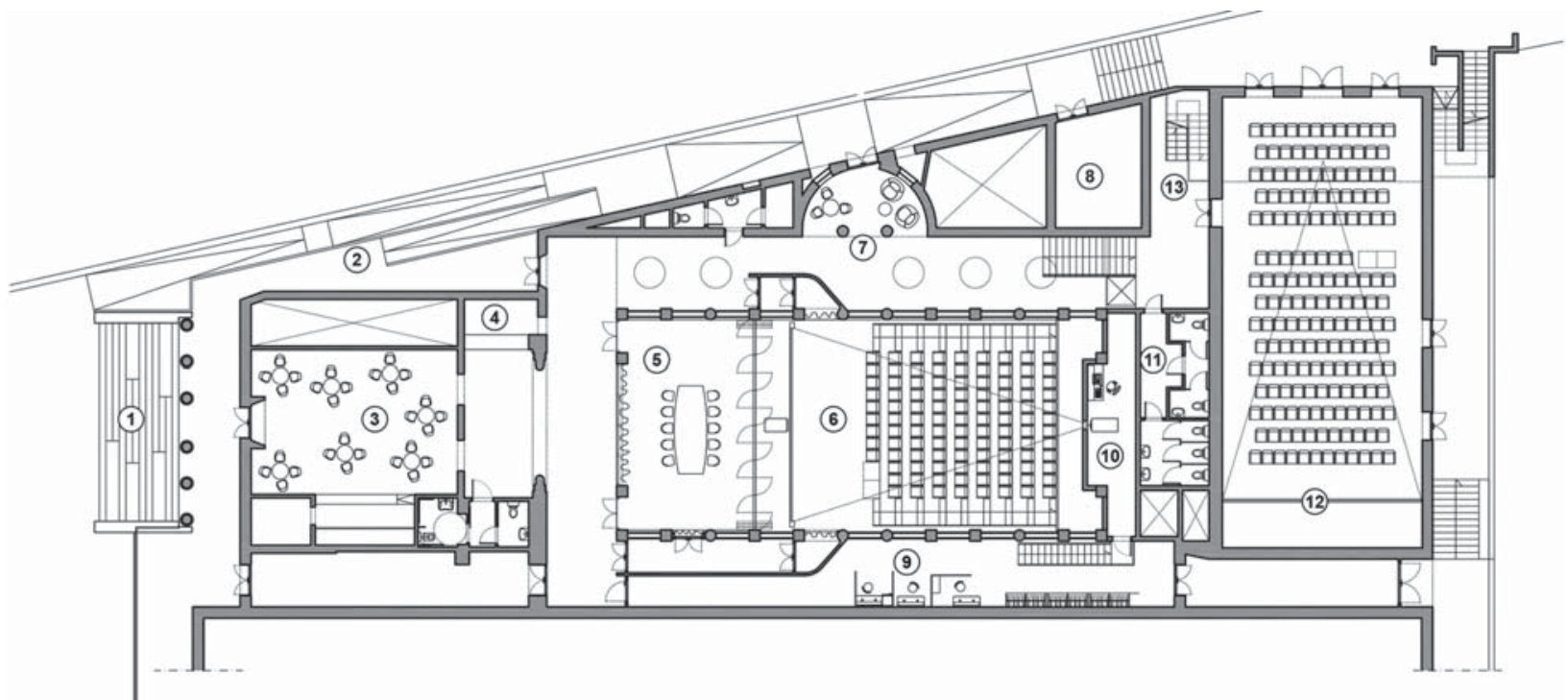




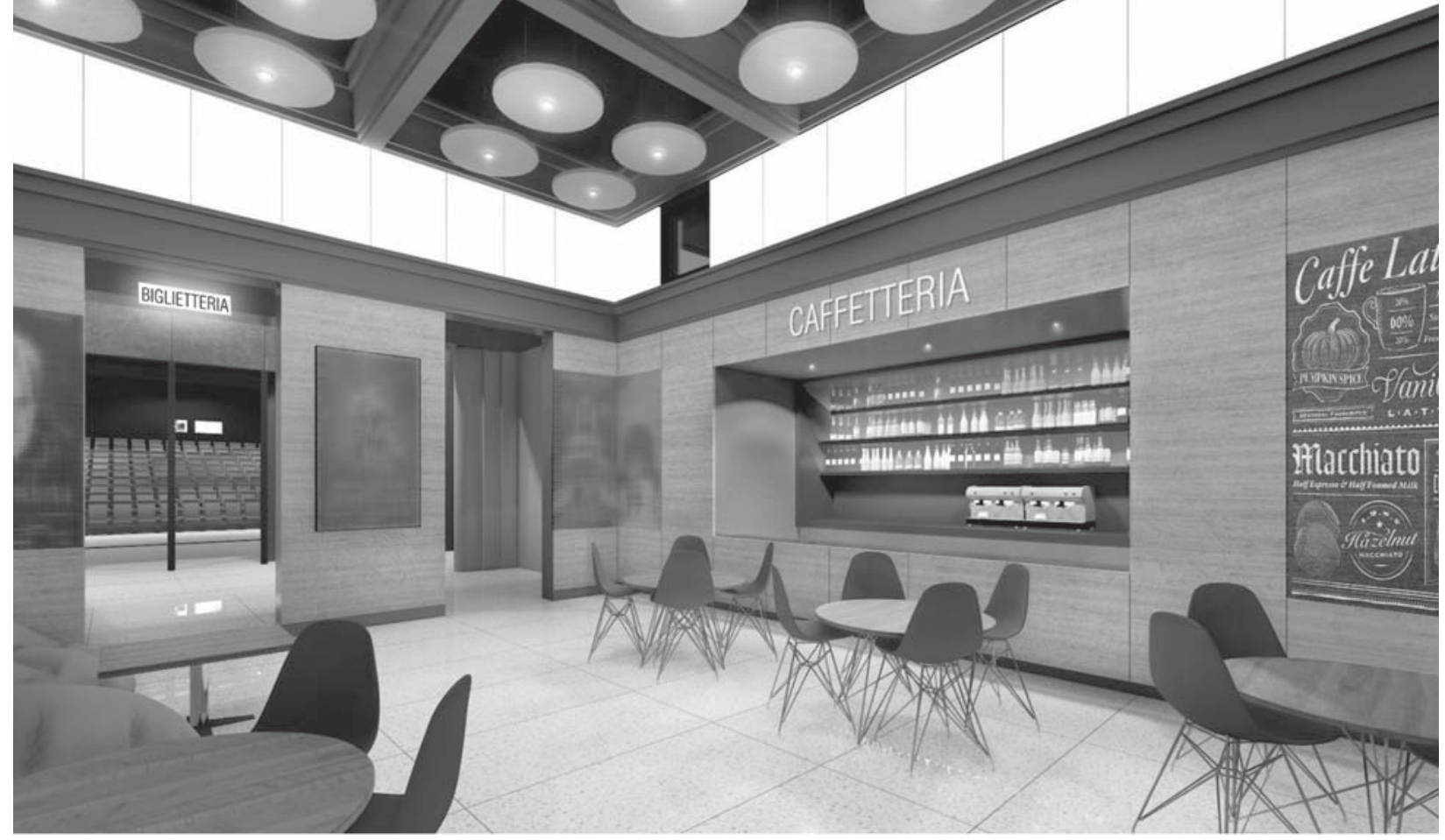

III. 10. Rendering of the new lobby/café. Prepared by R.M. Balzarotti, L.M.F. Fabris

too conventional, but having someone on site, in charge of the centre's day-to-day management, would be the first step to give life to this architecture.

\section{Defining a new model of Community Cinema}

Considering the intrinsic values of the Community Cinema and the current scenario in the commercial cinemas, two possible keywords emerged to drive the process of the redesign of spaces managed by the ACEC: multi-

III. 11. Rendering of the new multi-purpose room with retractable bleachers. Prepared by R.M. Balzarotti, L.M.F. Fabris
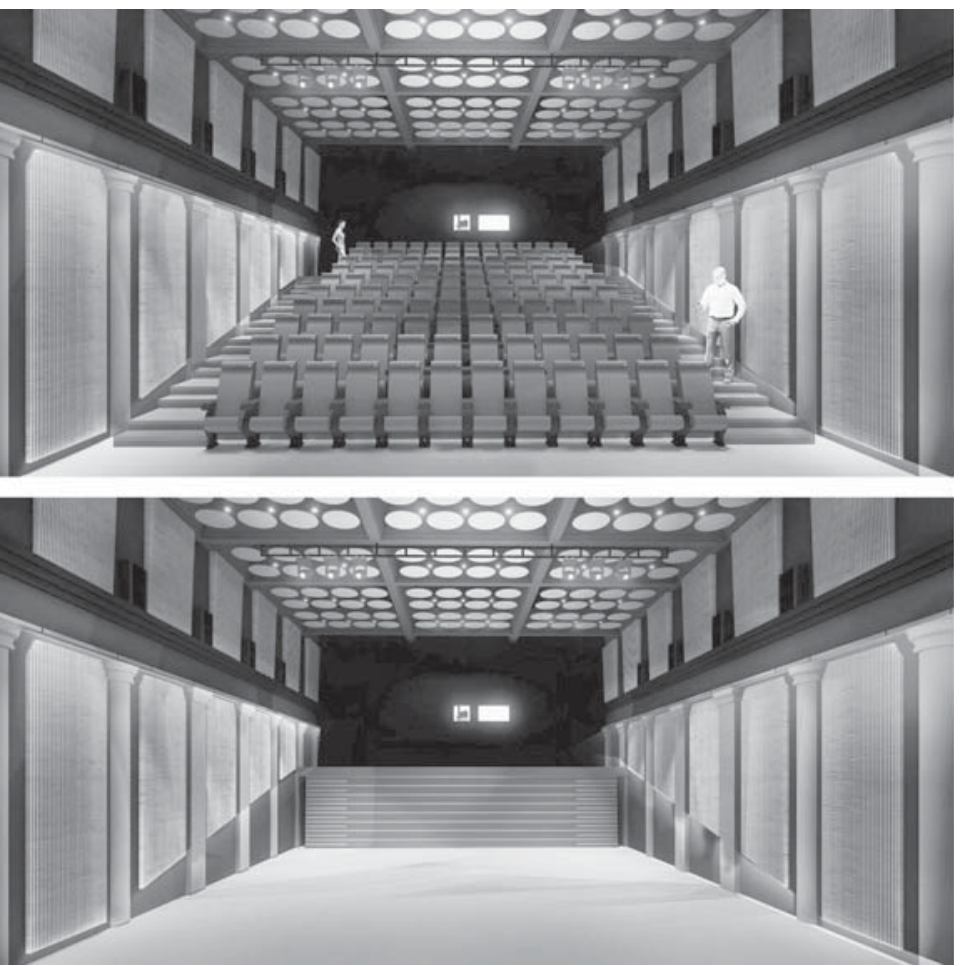

purpose space and social aggregation. The basis of the new cinema space for urban regeneration is distinguished by a wide overview of services and activities that can respond to the social needs of spending quality time together, immersed in a welcoming environment equipped with specific technologies that can offer an experience different (and better) from home-cinema alternatives.

These two goals have been fundamental throughout the history of the Community Cinemas. It is possible to say that in order to imagine the future of these spaces; it is necessary to re-think their deepest past. If even the commercial multiplex inside the suburban shopping malls are trying to transform themselves from non-places to places, adopting at least part of the same strategies implemented in the 'Anteo Palazzo del Cinema', the Community Cinemas have always been identified as 'places' related to a local community. Today they can use this strategic advantage to again mark their role in the urban and suburban scenario with a radical modification of their architectonic structure. A multidirectional, complex, polycentric space, provided with multiple points of accessibility and interconnected rooms, permeable in a physical and figurative way, transformable to accommodate different typologies of spectacles and events. They must be visible from the outside, give the idea of openness and create a dialogue between the interior and the neighbourhood. They should offer state-of-the-art technologies to facilitate integration with digital audio-visual media platforms.

In the end, the goal of renovating a Community Cinema should overcome the idea of just making a container dedicated to the consumption of products and goods. The architectural space, the way to live in this space with other members of the community and the services offered should create 
a homogenous image that can be intended as a value in itself.

In this idea, a Community Cinema should also expand its boundaries and be the spark for an urban regeneration processes that affects an entire neighbourhood or small town, promoting synergies between the existing institution and social actors. This can happen with the introduction of functions that are non-standard for a cinema and not that usual for a cultural centre. The proposal is to consider functions that can keep the space alive and active all day long, considering that the cinema alone has a very short time of usage per day and it is a service just for the people who go there purposely to watch a movie. The list of these activities is wide (Balzarotti, Fabris, 2018, pp. 34-41)7 and includes, as a reference, a long-permanence cafeteria, a small school that offer cinema-related classes and a 'neighbourhood reception'. The last one is a space for the local community to receive all the services that were normally performed by the door attendant of a building. Receiving shipments (they are becoming more and more frequent thanks to online shopping) or managing apartment keys (related to the growth of short-stay rentals); it can also be a small marketplace or a bulletin board for the neighbourhood with a digital extension through social media or websites.

\section{ENDNOTES}

1 Brunella E., 96\% of Europe's screens are digital, but not all countries have yet completed the digital transition, in: European cinema Journal Media Salles, iss. $1 / 2016$, p. 2

2 Cipriani L., Parrini M., Vademecum Sale della Comunità. Progettazione, Realizzazione, Normative e Indicazioni Operative, ACEC, Milano 2006. The complete list of the Sale della Comunità is published as an appendix, but no specification about their status is provided.
${ }^{3}$ Bourlot A., Fanchi M., I Nuovi Cinema Paradiso, Vita e Pensiero, Milano 2017. This study conducted by the Università Cattolica di Milano provides all the figures about the typology of functions and users in the Sale della Comunità.

${ }^{4}$ Balzarotti R.M. Fabris L.M.F. La Sala del Futuro. Linee Guida per la Rigenerazione delle Sale della Comunità, Maggioli, Santarcangelo di Romagna 2018. The comparison between commercial cinemas and community cinemas in the four areas of the case-studies showed that there is a trend in commercial cinemas to choose a solution with smaller rooms in terms of number of seats.

5 Source: ANICA, Yearly Report, 2018, available at http://www.anica. it/allegati/dati cinema 2017.pdf (retrieved on 28.07.2020). In the 2018 publication there is a precise indication about the revenue of the Italian cinemas based on the number of projection screens per cinema. Single screen: Euro 76.683; 2 to 4 screens: Euro 109.775; 5 to 7 screens: Euro 170.520; more than 7 screens: Euro 243.079.

${ }^{6}$ Translated from the original interview in Italian: Pasquale A., Le sale cinematografiche: combattere o convivere? Intervista a Lionello Cerri, Andrea Occhipinti, Andrea Stratta, in: Bianco e Nero, year LXXX, iss. 594/595, 2019, p. 132-141

7 Ibid. 4. The complete list provided by Balzarotti and Fabris is longer and includes the idea of having art galleries, temporary markets, and services for the community such as analog-to-digital conversions.

\section{REFERENCES}

[1] Balzarotti R.M., Fabris L.M.F, La Sala del Futuro. Linee Guida per la Rigenerazione delle Sale della Comunità, Maggioli, Santarcangelo di Romagna 2018

[2] Bourlot A., Fanchi M., I Nuovi Cinema Paradiso, Vita e Pensiero, Milano 2017

[3] Brunella E., 96\% of Europe's screens are digital, but not all countries have yet completed the digital transition, in: European cinema Journal Media Salles, iss. 1/2016, p. 2

[4] Cipriani L., Parrini M., Vademecum Sale della Comunità. Progettazione, Realizzazione, Normative e Indicazioni Operative, ACEC, Milano 2006

[5] Pasquale A., Le sale cinematografiche: combattere o convivere? Intervista a Lionello Cerri, Andrea Occhipinti, Andrea Stratta, in: Bianco e Nero, year LXXX, iss. 594/595, 2019, pp. 132-141

\section{WEB-BASED SOURCES}

[1] ANICA, Yearly Report, 2018, available at http://www.anica.it/allegati/dati_cinema_2017.pdf (accessed on: 28.07.2020) 